\title{
Pemodelan UML Sistem Informasi Administrasi Kependudukan Untuk Kantor Desa
}

\author{
$\underline{\text { Eri Bayu Pratama }}{ }^{1}$ Ucok Saparingga ${ }^{2}$ \\ Sistem Informasi, Fakultas Teknik dan Informatika, Universitas Bina Sarana Informatika \\ Jl. Abdurrahman Saleh No.18 A, Pontianak, Indonesia \\ eri.ebp@bsi.ac.id ${ }^{1}$,viktorinusucok@gmail.com ${ }^{2}$
}

\begin{abstract}
Most agencies currently switch to the use of computers for population data management, one of them is the Village Office as a public service. However, some population administration systems applied has not been integrated into the database, such as recording birth data, death data and population mutations that still use Microsoft Excel. This research discusses how to find out population information which includes data on new population arrivals, displacement, births, and permanent population data by implementing a web-based information system. To complete the design of this information system, several data collection techniques are needed, namely observation, interviews and literature study. The three techniques are carried out in stages in order to qualify the user requirements. So, the UML (Unified and class diagrams can provide an overview and explanation of a directed system work process and use the system according to user needs.Modeling Language) modeling which is explained through Use case diagrams, Sequence diagrams, activity diagrams.
\end{abstract}

Keywords: uml modelling, population administration system

\begin{abstract}
Abstrak
Kebanyakan instansi saat ini beralih pada pengelolaan data penduduk dengan komputer, salah satu diantaranya adalah Kantor Desa dengan kegiatan utamanya adalah pelayanan penduduk. Hanya saja beberapa sistem kerja administrasi kependudukan yang diterapkan belum terintegrasi ke database, seperti pencatatan data kelahiran, data kematian dan mutasi penduduk yang masih menggunakan Microsoft Excel. Penelitian ini membahas mengenai bagaimana mengetahui informasi kependudukan yang meliputi data kedatangan penduduk baru, perpindahan, kelahiran, dan data penduduk tetap dengan menerapkan sistem informasi berbasis web. Pengumpulan data yang dikumpulkan untuk menyelesaikan perancangan sistem informasi ini menggunakan teknik pengumpulan data observasi, wawancara dan studi pustaka. Ketiga teknik tersebut dilakukan secara bertahap agar dapat memenuhi kebutuhan sistem secara lengkap. Sehingga pemodelan UML (Unified Modelling Language) yang dijelaskan melalui Use case diagram, Sequence diagram, acticity diagram dan class diagram dapat memberikan gambaran serta penjelasan tentang suatu proses kerja sistem secara terarah dan penggunaan sistem sesuai kebutuhan pengguna.
\end{abstract}

Kata kunci : pemodelan uml, sistem administrasi kependudukan

\section{Pendahuluan}

Pada dasarnya masyarakat harus belajar dan mengetahui sistem komputer adalah merupakan tahap awal manusia mengetahui teknologi informasi dan sistem tersebut dapat dikembangkan lagi menjadi suatu sistem informasi seperti penyediaan data informasi yang tepat dan cepat. Perkembangan teknologi pada sistem informasi saat ini telah mempermudah pemrosesan informasi yang dibutuhkan sehingga informasi yang disebarkan dapat lebih mudah, jelas, cepat dan lengkap. Hal ini, disebabkan teknologi informasi dibutuhkan oleh masyarakat dalam hal kegiatan seperti orang yang bekerja sebagai administrasi dan diperlukan suatu sistem informasi yang cepat dan tepat [1].

Internet menjadi perhatian yang serius dalam percepatan perkembangan era teknologi informasi saat ini. Internet yang merupakan kependekan dari interconnection-networking sudah sangat banyak digunakan oleh masyarakat diberbagai kalangan. Internet dapat dimanfaatkan dalam segala bidang, untuk bidang pendidikan, pemerintah, bisnis, kesehatan, sosial dan masih banyak lagi. Bagian terpenting dalam internet untuk bisnis adalah website. Website merupakan suatu halaman web yang berisi informasi yang disediakan secara perorangan, kelompok atau organisasi. Pada dunia bisnis, website dapat membuat produk atau jasa dikenal dan diakses oleh jutaan orang. Website akan menunjang image dari perusahaan atau instansi dimata pelanggan [2]. 
Administrasi kependudukan dengan kata dasar adalah administrasi dan kependudukan, merupakan suatu kegiatan yang melibatkan sumber daya manusia [3]. Seperti hal pengelolaan data penduduk merupakan tanggung jawab pemerintah kabupaten atau kota dimana dalam pelaksanaannya diawali dari desa atau kelurahan. Dalam pelayanan pengurusan administrasi baik itu pendaftaran penduduk maupun pembuatan surat keterangan yang lainnya perlu dilakukan dengan benar dan cepat agar penduduk dapat merasa mendapatkan pelayanan yang memuaskan [4].

Pemanfaatan penggunaan komputer sudah diterapkan pada kantor desa saat ini dalam kegiatan pelayanan penduduk. Akan tetapi proses atau sistem kerja yang diterapkan masih ada yang belum memiliki program khusus yang terintegrasi ke database dalam hal administrasi kependudukan seperti pencatatan data kelahiran, kematian dan mutasi penduduk masih menggunakan buku besar atau buku register, dan dengan menggunakan Microsoft Excel sebagai penginputan data penduduk. Peneliti menguraikan permasalahan dan mempunyai solusi dengan cara dibuatkan sebuah rancangan sistem infromasi administrasi kependudukan yang terkomputerisasi serta terintegrasi agar mempemudah dalam pengelolaan data penduduk.

\section{Metodologi}

Untuk dapat membantu menyelesaikan penelitian ini, peneliti menggunakan beberapa metode yang peneliti tuangkan pada penelitian ini. Pada pengumpulan data yang peneliti gunakan, peneliti menggunakan tiga teknik pengumpulan data diantaranya: Observasi untuk mengetahui kebutuhan sistem dan user, wawancara dengan melakukan diskusi untuk mengetahui terkait permasalahan yang ada terkait informasi administrasi kependudukan, dan studi pustaka dengan mencari sumber dari referensi baik penelitian terdahulu melalui jurnal dan artikel yang melakukan penelitian sejenis. Selain itu pada tahap perancangan sistem ini menggunakan model UML yang menggambarkan proses tahapan pembuatan dan kerja sistem dari beberapa diagram yang digunakan diantaranya: Use case diagram, Sequence diagram, activity diagram dan class diagram. Berikut penjelasan dari metode yang peneliti gunakan:

\subsection{UML (Unified Modelling Language)}

Untuk menggambarkan suatu proses kerja sistem peneliti menggunakan UML yang merupakan suatu bahasa pemodelan dengan tujuan umum yang standar di bidang ilmu komputer dan rekayasa perangkat lunak, sehingga kerangka kerja yang digunakan menggunakan diagram use case untuk menggambarkan urutan proses kerja sistem [5]. Terdapat dua pandangan yang berbeda pada sistem model UML ini yang dimana penggambarannya adalah UML merupakan suatu alat yang digunakan untuk menentukan dan menggambarkan secara visual sistem perangkat lunak termasuk tipe diagram standar pada aplikasi komputer atau desain dan struktur sistem database, dan berikut dua pandangan tersebut [6]:

1. Tampilan statis (atau struktural): menekankan pada struktur statis sistem yang menggunakan objek, atribut, operasi, dan penghubungan. Pandangan struktural termasuk diagram kelas dan diagram struktur komposit.

2. Tampilan dinamis (atau perilaku): menekankan pada perilaku dinamis sistem dengan menunjukkan kolaborasi di antara objek dan perubahan pada status objek internal. Pandangan ini termasuk sequence diagram, activity diagram dan state machine diagram.

UML juga digunakan untuk menghasilkan kode dalam berbagai bahasa dari deskripsi diagram serta memiliki hubungan langsung dengan analisis dan desain berorientasi objek dan dapat menyertakan notasi grafis yang dapat digunakan untuk membuat model abstrak dari suatu sistem dengan tujuan umum dari UML adalah untuk membuat sistem mudah dipahami dan digunakan oleh pengguna dan pengembang [7].

\subsection{Teknik Pengumpulan Data}

Teknik pengumpulan data merupakan suatu teknik yang digunakan dalam pengumpulan data-data terkait dengan penelitian ini terdari dari observasi, wawancara dan studi pustaka. Adapun penjelasan dari teknik pengumpulan data yang digunakan dan diuraikan sebagai berikut : 
1. Observasi

Melakukan observasi secara langsung bagaimana kebutuhan sistem dan user pada beberapa Kantor Desa. Obeservasi dilakukan pada bagian administrasi kependudukan untuk mendapatkan hasil tentang permasalahan yang sering terjadi.

2. Wawancara

Untuk mendapatkan data informasi yang jelas dari Kantor Desa dengan wawancara atau Interview dengan menanyakan masalah yang dihadapi dibagian administrasi kependudukan agar menemukan solusi agar kantor desa dapat mengatasi masalah tersebut dengan perancangan administrasi kependudukan ini.

3. Studi Pustaka

Mengumpulkan data serta informasi dengan cara mencari dan membaca teori-teori referensi penelitian seperti jurnal, artikel, tulisan yang bersumber dari internet dan referensi yang berkaitan dengan penelitian.

\section{Hasil dan Pembahasan}

\subsection{Rancangan Use Case Diagram}

Rancangan sistem yang diusulkan ini dimodelkan ke dalam use case diagram yang dimana menjelaskan secara visual konteks dari interaksi antara aktor dengan sistem [8]. Hasil pemodelan rancangan menggunakan use case diagram ini dapat dilihat pada halaman berikut.

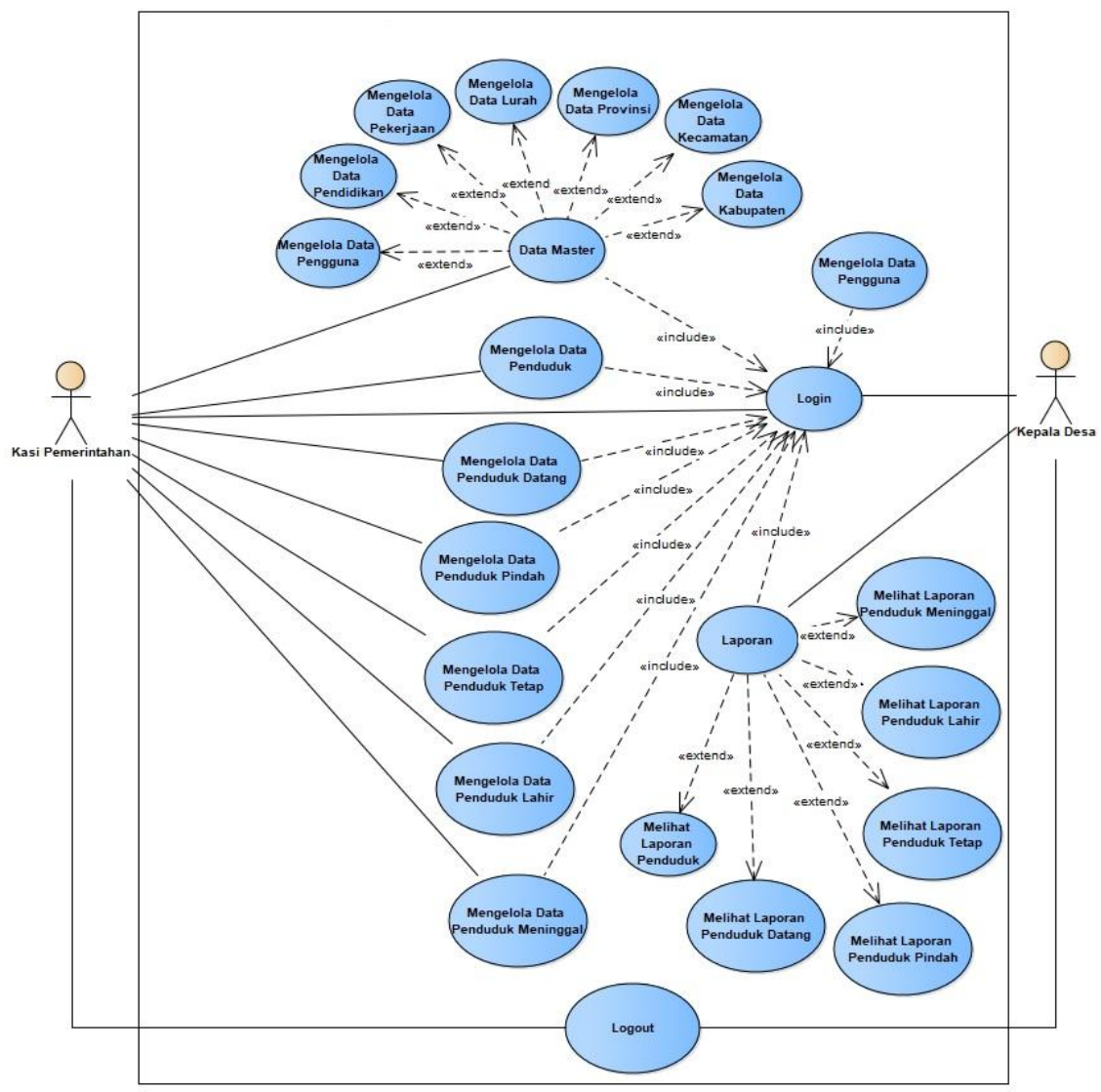

Gambar 1. Use Case Diagram

Berikut penjelasan dari kasus-kasus ataupun kejadian dari aktor di use case tersebut dalam menggunakan sistem untuk menyelesaikan sebuah proses [9], berikut penjelasannya dalam bentuk tabel:

a. Pada tabel ini menjelaskan proses login yang dilakukan oleh aktor kasi pemerintahan dan kepada desa untuk melakukan login ke sistem. 
Tabel 1. Use case Login

\begin{tabular}{|c|c|}
\hline Use Case Name & Melakukan Login \\
\hline Requeirements & $\begin{array}{l}\text { Kasi Pemerintahan dan Kepala Desa dapat melakukan login untuk } \\
\text { masuk ke program }\end{array}$ \\
\hline Goal & $\begin{array}{l}\text { Kasi Pemerintahan dan Kepala Desa dapat melakukan login saat } \\
\text { memasuki program }\end{array}$ \\
\hline Pre-Conditions & Kasi Pemerintahan dan Kepala Desa telah melakukan login \\
\hline Post-Condition & $\begin{array}{l}\text { Kasi Pemerintahan dan Kepala Desa dapat melakukan login pada } \\
\text { saat akan mengakses menu utama }\end{array}$ \\
\hline Failed-Condition & Salah mengisi username dan password \\
\hline Actors & $\begin{array}{l}\text { 1. Kasi Pemerintahan } \\
\text { 2. Kepala Desa }\end{array}$ \\
\hline Main Flow/Basic & 1. Kasi Pemerintahan dan Kepala Desa membuka aplikasi \\
\hline Path & $\begin{array}{l}\text { 2. Kasi Pemerintahan dan Kepala Desa mengisi username dan } \\
\text { password } \\
\text { 3. Kasi Pemerintahan dan Kepala Desa dapat mengakses aplikasi } \\
\text { utama sesuai dengan level akses }\end{array}$ \\
\hline $\begin{array}{l}\text { Alternative Flow } \\
\text { /Invariant A }\end{array}$ & $\begin{array}{l}\text { Kasi Pemerintahan dan Kepala Desa dapat melakukan login saat } \\
\text { akan mengakses program }\end{array}$ \\
\hline Invariant $B$ & $\begin{array}{l}\text { 1. Kasi Pemerintahan dan Kepala Desa memasukan username } \\
\text { 2. Kasi Pemerintahan dan Kepala Desa memasukan password } \\
\text { 3. Sistem tidak dapat menemukan user dengan username atau } \\
\text { password yang telah dimasukkan } \\
\text { 4. Sistem menampilkan pesan username atau password salah }\end{array}$ \\
\hline
\end{tabular}

b. Pada tabel ini menjelaskan tentang actor kasi pemerintahan dan kepala desa dapat melakukan kelola data pengguna.

Tabel 2. Use case Kelola Data Pengguna

\begin{tabular}{ll}
\hline Use Case Name & Mengelola Data Pengguna \\
Requeirements & Kasi Pemerintahan dan Kepala Desa dapat mengelola data pengguna \\
Goal & $\begin{array}{l}\text { Kasi Pemerintahan dan Kepala Desa dapat mengelola data pengguna } \\
\text { pada menu utama }\end{array}$ \\
Pre-Condition & Kasi Pemerintahan dan Kepala Desa telah melakukan login \\
Post-Condition & $\begin{array}{l}\text { Kasi Pemerintahan dan Kepala Desa dapat mengelola data pengguna } \\
\text { pada menu data master }\end{array}$ \\
Failed-Condition & $\begin{array}{l}\text { Data belum lengkap } \\
\text { Actors }\end{array}$ \\
$\begin{array}{l}\text { 1. Kain Flow/Basic } \\
\text { Path }\end{array}$ & $\begin{array}{l}\text { 1. } \text { Kepala Desa } \\
\text { Kasi Pemerintahan dan Kepala Desa mengisi data pengguna jika } \\
\text { ada yang ing bekerja sebagai administrasi atau kasi } \\
\text { pemerintahan }\end{array}$ \\
& $\begin{array}{l}\text { 2. Kasi Pemerintahan dan Kepala Desa dapat melihat data } \\
\text { pengguna }\end{array}$
\end{tabular}


3. Kasi Pemerintahan dan Kepala Desa dapat menyimpan data pengguna

Alternative Flow / Kasi Pemerintahan dan Kepala Desa dapat mengisi data pengguna Invariant $A$ pada form data pengguna

Invariant B

1. Kasih Pemerintahan dan Kepala Desa mengisi data pengguna

2. Kasi Pemerintahan dan Kepala Desa dapat melihat data pengguna

3. Kasi Pemerintahan dan Kepala Desa dapat menyimpan data pengguna

c. Pada tabel ini menjelaskan tentang actor kasi pemerintahan dapat melakukan kelola data penduduk.

Tabel 3. Use case kelola data penduduk

\begin{tabular}{|c|c|}
\hline Use Case Name & Mengelola Data Penduduk \\
\hline Requeirements & Kasi Pemerintahan dapat mengelola data penduduk \\
\hline Goal & Kasi Pemerintahan dapat memasukan data penduduk \\
\hline Pre-Condition & Kasi Pemerintahan telah melakukan login \\
\hline Post-Condition & $\begin{array}{l}\text { Kasi Pemerintahan dapat mengelola data penduduk pada menu data } \\
\text { penduduk }\end{array}$ \\
\hline Failed-Condition & Data belum lengkap \\
\hline Actors & Kasi Pemerintahan \\
\hline $\begin{array}{l}\text { Main Flow/Basic } \\
\text { Path }\end{array}$ & $\begin{array}{l}\text { 1. Kasi Pemerintahan mengisi data penduduk jika ada penduduk yang } \\
\text { mengajukan permohonan } \\
\text { 2. Kasi Pemerintahan dapat melihat data penduduk } \\
\text { 3. Kasih Pemerintahan dapat menyimpan data penduduk }\end{array}$ \\
\hline $\begin{array}{l}\text { Alternative Flow } \\
\text { / Invariant A }\end{array}$ & $\begin{array}{l}\text { Kasi Pemerintahan dapat mengisi data penduduk pada form data } \\
\text { penduduk }\end{array}$ \\
\hline Invariant $B$ & $\begin{array}{l}\text { 1. Kasi Pemerintahan mengisi data penduduk } \\
\text { 2. Kasi Pemerintahan dapat melihat data penduduk } \\
\text { 3. Kasi Pemerintahan dapat menyimpan data penduduk }\end{array}$ \\
\hline
\end{tabular}

d. Pada tabel ini menjelaskan tentang actor kasi pemerintahan dapat melakukan kelola data kedatangan penduduk.

Tabel 4. Use case kelola Kedatangan Penduduk

$\begin{array}{ll}\text { Use Case Name } & \text { Mengelola Data Penduduk Datang } \\ \text { Requeirements } & \text { Kasi Pemerintahan dapat mengelola data penduduk datang } \\ \text { Goal } & \text { Kasi Pemerintahan dapat memasukan data penduduk datang } \\ \text { Pre-Condition } & \text { Kasi Pemerintahan telah melakukan login } \\ \text { Post-Condition } & \begin{array}{l}\text { Kasi Pemerintahan dapat mengelola data penduduk datang pada menu } \\ \text { data penduduk }\end{array}\end{array}$




\section{Failed-Condition Data belum lengkap}

Actors Kasi Pemerintahan

Main Flow/Basic 1. Kasi Pemerintahan mengisi data penduduk datang jika ada yang

Path mengajukan permohonan

2. Kasi Pemerintahan dapat melihat data penduduk datang

3. Kasih Pemerintahan dapat menyimpan data penduduk datang

Alternative Flow Kasi Pemerintahan dapat mengisi data penduduk datang pada form data

/Invariant $A \quad$ penduduk datang

Invariant B $\quad$ 1. Kasi Pemerintahan mengisi data penduduk datang

2. Kasi Pemerintahan dapat melihat data penduduk datang

3. Kasi Pemerintahan dapat menyimpan data penduduk datang

e. Pada tabel ini menjelaskan tentang actor kasi pemerintahan dapat melakukan kelola kepindahan data penduduk.

Tabel 5. Use case kelola kepindahan penduduk

\begin{tabular}{|c|c|}
\hline Use Case Name & Mengelola Data Penduduk Pindah \\
\hline Requeirements & Kasi Pemerintahan dapat mengelola data penduduk pindah \\
\hline Goal & Kasi Pemerintahan dapat memasukan data penduduk pindah \\
\hline Pre-Condition & Kasi Pemerintahan telah melakukan login \\
\hline Post-Condition & $\begin{array}{l}\text { Kasi Pemerintahan dapat mengelola data penduduk pindah pada menu } \\
\text { data penduduk }\end{array}$ \\
\hline Failed-Condition & Data belum lengkap \\
\hline Actors & Kasi Pemerintahan \\
\hline $\begin{array}{l}\text { Main Flow/Basic } \\
\text { Path }\end{array}$ & $\begin{array}{l}\text { 1. Kasi Pemerintahan mengisi data penduduk pindah jika ada yang } \\
\text { mengajukan permohonan } \\
\text { 2. Kasi Pemerintahan dapat melihat data penduduk pindah } \\
\text { 3. Kasih Pemerintahan dapat menyimpan data penduduk pindah }\end{array}$ \\
\hline $\begin{array}{l}\text { Alternative Flow / } \\
\text { Invariant A }\end{array}$ & $\begin{array}{l}\text { Kasi Pemerintahan dapat mengisi data penduduk pindah pada form data } \\
\text { penduduk pindah }\end{array}$ \\
\hline Invariant $B$ & $\begin{array}{l}\text { 1. Kasi Pemerintahan mengisi data penduduk pindah } \\
\text { 2. Kasi Pemerintahan dapat melihat data penduduk pindah } \\
\text { 3. Kasi Pemerintahan dapat menyimpan data penduduk pindah }\end{array}$ \\
\hline
\end{tabular}

f. Pada tabel ini menjelaskan tentang actor kasi pemerintahan dapat melakukan kelola data penduduk tetap.

Tabel 6. Use case kelola data penduduk tetap

$\begin{array}{ll}\text { Use Case Name } & \text { Mengelola Data Penduduk Tetap } \\ \text { Requeirements } & \text { Kasi Pemerintahan dapat mengelola data penduduk tetap } \\ \text { Goal } & \text { Kasi Pemerintahan dapat memasukan data penduduk tetap } \\ \text { Pre-Condition } & \text { Kasi Pemerintahan telah melakukan login }\end{array}$




\begin{tabular}{|c|c|}
\hline Post-Condition & $\begin{array}{l}\text { Kasi Pemerintahan dapat mengelola data penduduk tetap pada menu data } \\
\text { penduduk }\end{array}$ \\
\hline Failed-Condition & Data belum lengkap \\
\hline Actors & Kasi Pemerintahan \\
\hline $\begin{array}{l}\text { Main Flow/Basic } \\
\text { Path }\end{array}$ & $\begin{array}{l}\text { 1. Kasi Pemerintahan mengisi data penduduk tetap jika ada yang } \\
\text { mengajukan permohonan } \\
\text { 2. Kasi Pemerintahan dapat melihat data penduduk tetap } \\
\text { 3. Kasih Pemerintahan dapat menyimpan data penduduk tetap }\end{array}$ \\
\hline $\begin{array}{l}\text { Alternative Flow / } \\
\text { Invariant A }\end{array}$ & $\begin{array}{l}\text { Kasi Pemerintahan dapat mengisi data penduduk pindah pada form data } \\
\text { penduduk tetap }\end{array}$ \\
\hline Invariant $B$ & $\begin{array}{l}\text { 1. Kasi Pemerintahan mengisi data penduduk tetap } \\
\text { 2. Kasi Pemerintahan dapat melihat data penduduk tetap } \\
\text { 3. Kasi Pemerintahan dapat menyimpan data penduduk tetap }\end{array}$ \\
\hline
\end{tabular}

g. Pada tabel ini menjelaskan tentang actor kasi pemerintahan dapat melakukan kelola data kelahiran penduduk.

Tabel 7. Use case kelola kelahiran penduduk

\begin{tabular}{|c|c|}
\hline Use Case Name & Mengelola Data Penduduk Lahir \\
\hline Requeirements & Kasi Pemerintahan dapat mengelola data penduduk lahir \\
\hline Goal & Kasi Pemerintahan dapat memasukan data penduduk lahir \\
\hline Pre-Condition & Kasi Pemerintahan telah melakukan login \\
\hline Post-Condition & $\begin{array}{l}\text { Kasi Pemerintahan dapat mengelola data penduduk lahir pada menu } \\
\text { data penduduk }\end{array}$ \\
\hline Failed-Condition & Data belum lengkap \\
\hline Actors & Kasi Pemerintahan \\
\hline $\begin{array}{l}\text { Main Flow/Basic } \\
\text { Path }\end{array}$ & $\begin{array}{l}\text { 1. Kasi Pemerintahan mengisi data penduduk lahir jika ada yang } \\
\text { mengajukan permohonan } \\
\text { 2. Kasi Pemerintahan dapat melihat data penduduk lahir } \\
\text { 3. Kasih Pemerintahan dapat menyimpan data penduduk lahir }\end{array}$ \\
\hline $\begin{array}{l}\text { Alternative Flow / } \\
\text { Invariant A }\end{array}$ & $\begin{array}{l}\text { Kasi Pemerintahan dapat mengisi data penduduk lahir pada form data } \\
\text { penduduk lahir }\end{array}$ \\
\hline Invariant $B$ & $\begin{array}{l}\text { 1. Kasi Pemerintahan mengisi data penduduk lahir } \\
\text { 2. Kasi Pemerintahan dapat melihat data penduduk lahir } \\
\text { 3. Kasi Pemerintahan dapat menyimpan data penduduk lahir }\end{array}$ \\
\hline
\end{tabular}

h. Pada tabel ini menjelaskan tentang actor kasi pemerintahan dapat melakukan kelola data penduduk meninggal.

Tabel 8. Use case kelola data penduduk meninggal

\begin{tabular}{ll}
\hline Use Case Name & Mengelola Data Penduduk Meninggal \\
\hline Requeirements & Kasi Pemerintahan dapat mengelola data penduduk Meninggal \\
\hline Goal & Kasi Pemerintahan dapat memasukan data penduduk Meninggal
\end{tabular}




\begin{tabular}{ll}
\hline Pre-Condition & Kasi Pemerintahan telah melakukan login \\
\hline Post-Condition & $\begin{array}{l}\text { Kasi Pemerintahan dapat mengelola data penduduk meninggal pada menu } \\
\text { data penduduk }\end{array}$ \\
\hline Failed-Condition & Data belum lengkap \\
\hline Actors & Kasi Pemerintahan \\
\hline Main Flow/Basic & 1. Kasi Pemerintahan mengisi data penduduk meninggal jika ada yang \\
Path & mengajukan permohonan \\
& $\begin{array}{l}\text { 2. Kasi Pemerintahan dapat melihat data penduduk meninggal } \\
\text { 3. Kasih Pemerintahan dapat menyimpan data penduduk meninggal }\end{array}$ \\
\hline $\begin{array}{ll}\text { Alternative Flow / } & \text { Kasi Pemerintahan dapat mengisi data penduduk meninggal pada form } \\
\text { data penduduk meninggal }\end{array}$ \\
\hline Invariant B & $\begin{array}{l}\text { 1. Kasi Pemerintahan mengisi data penduduk meninggal } \\
\text { 2. Kasi Pemerintahan dapat melihat data penduduk meninggal }\end{array}$ \\
& 3. Kasi Pemerintahan dapat menyimpan data penduduk meninggal \\
\hline
\end{tabular}

\subsection{Rancangan Activity Diagram}

Activity Diagram berikut menjelaskan tentang alur dari aktivitas didalam system yang sedang dibuat, bagaimana masing-masing aktivitas dimulai, kejadian yang mungkin terjadi, serta bagaimana berakhirnya sistem tersebut [10]. Tahapan yang dilalui sistem diantaranya untuk melakukan pengelolaan data penduduk, pengelolaan tersebut seperti proses menambahkan, melakukan pembaruan data yang telah tersimpan, dan menghapus serta proses pencarian data.

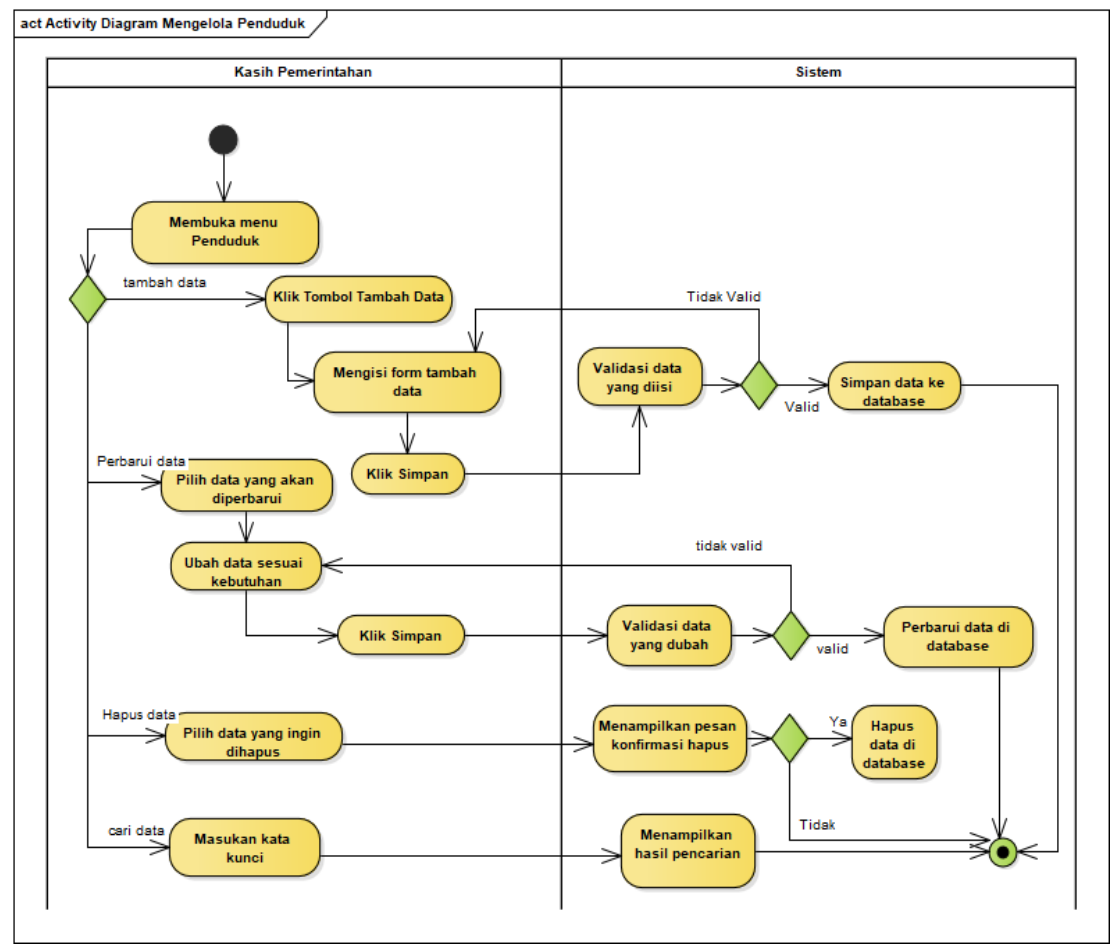

Gambar 2. Activity Diagram Kelola Data Penduduk

Activity Diagram mengelola penduduk datang menjelaskan tentang tahapan yang dilalui sistem untuk melakukan pengelolaan data penduduk datang. Yang memiliki akses adalah kasi pemerintahan dengan menggunakan fungsi menu tambah data sehingga memiliki akses untuk memanipulasi data seperti, 
menambahkan, menghapus, mengubah, menyimpan, mancari data, dan semua akses tersebut yang dilakukan divalidasi oleh sistem.

\subsection{Rancangan Sequence Diagram}

Berikut ini merupakan hasil rancangan sequence diagram untuk menggambarkan interaksi antara sejumlah objek dalam urutan waktu [11].

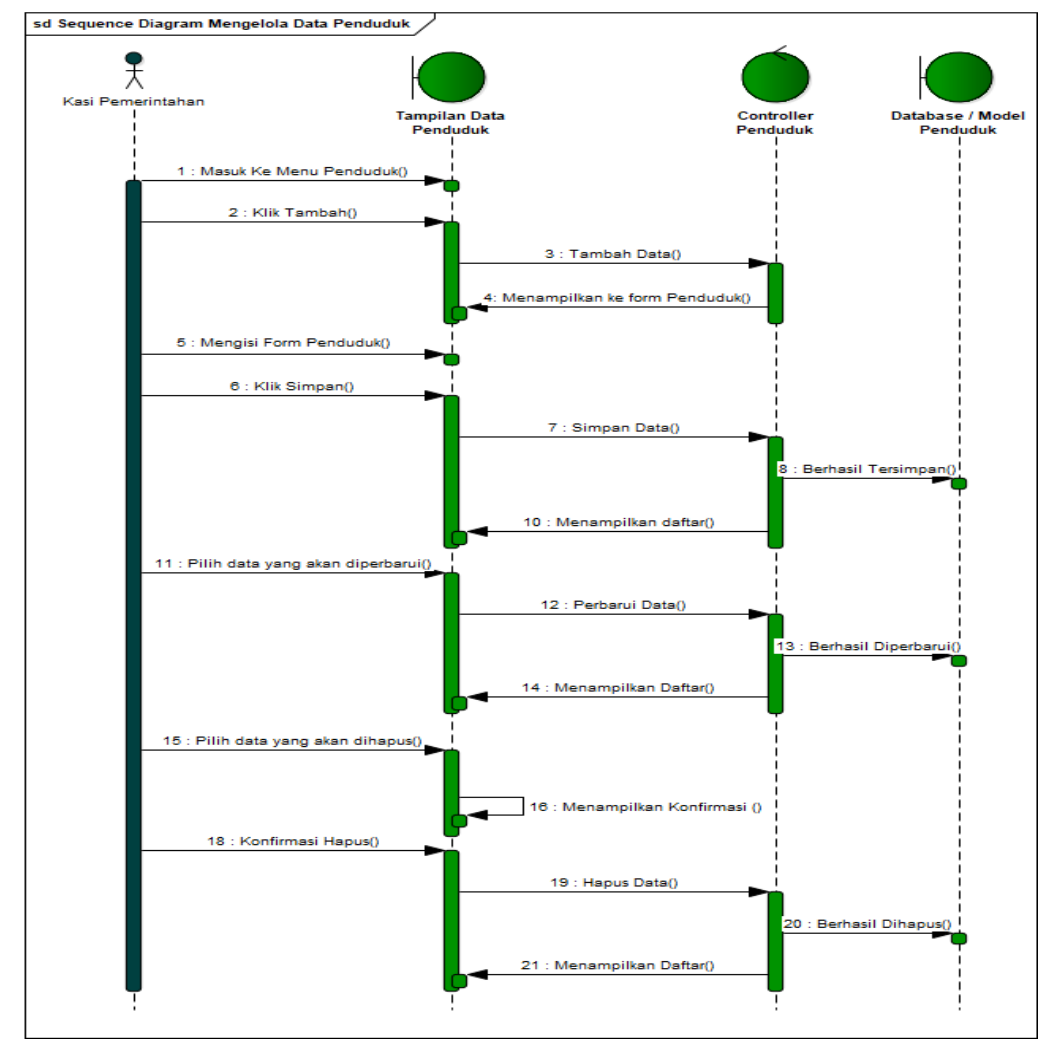

Gambar 3. Rancangan Sequence Diagram Kelola Data Penduduk

Sequence diagram mengelola penduduk menjelaskan tentang kasi pemerintahan yang dapat melakukan pengelolaan data penduduk, seperti menambahkan, memperbarui, menampilkan data, dan menghapus data.

\subsection{Rancangan Class Diagram}

Class diagram struktur sistem dari segi pendefinisian kelas-kelas atau kelas objek dan memperlihatkan aturan serta tanggung jawab entitas serta berisikan metode-metode atau aturan tertentu [12]. 


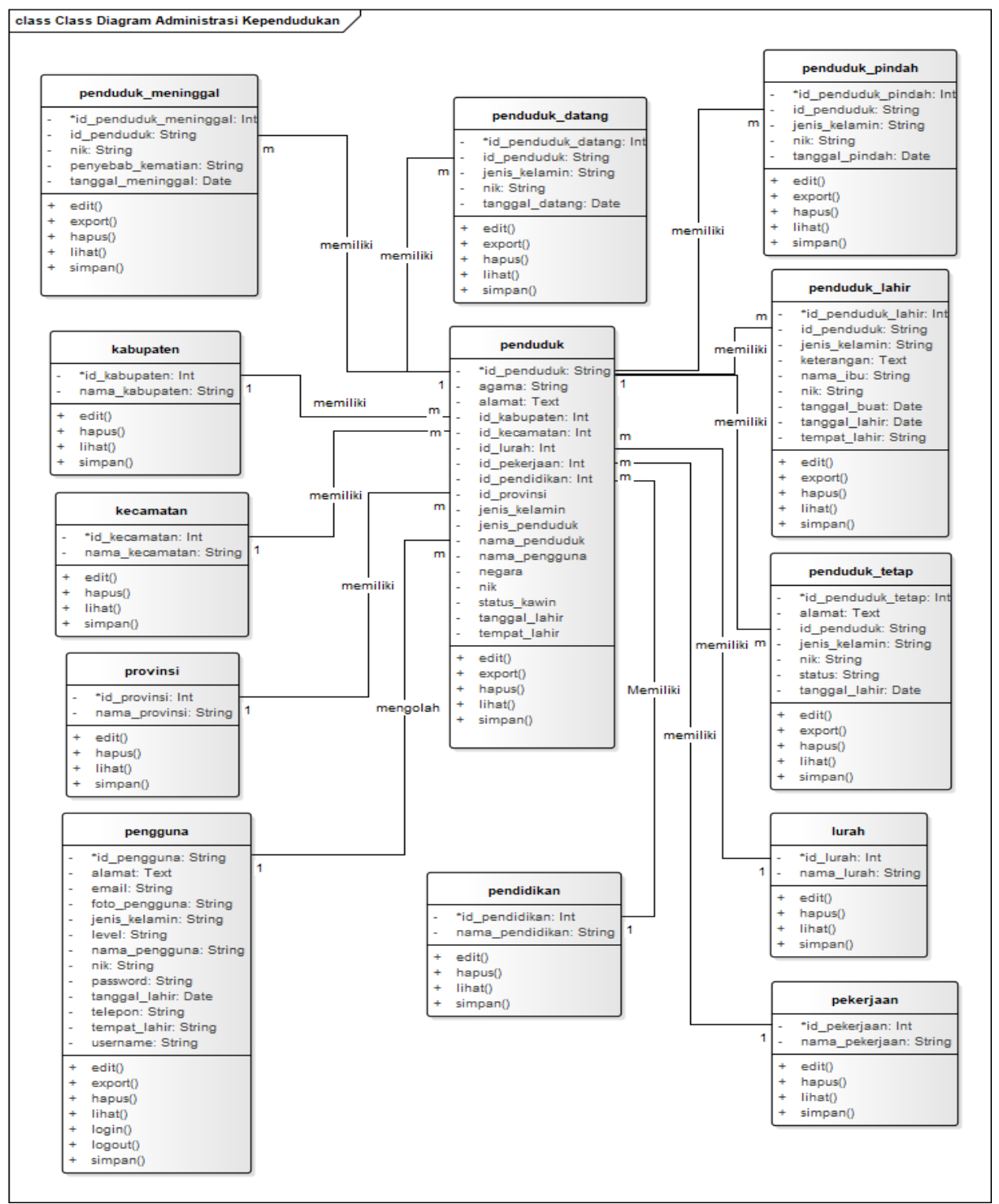

Gambar 4. Rancangan Class Diagram

Terdapat tiga belas entitas dalam perancangan sistem informasi ini, diantaranya penduduk_meninggal, penduduk datang, penduduk pindah, penduduk, penduduk lahir, penduduk tetap, pendidikan, pekerjaan, kabupaten, kecamatan, provinsi, pengguna. Semua entitas tersebut saling berelasi dengan entitas lainnya dan memiliki kardinilitas dari setiap entitas tersebut. Relasi serta kardinalitas tersebut menggambarkan tentang hubungan yang terjadi antar entitas agar dalam pengelolaan pada data dapat tersinkronisasi dengan baik sehingga tidak terjadi kesalahan serta redudansi data.

\subsection{Interface}

Interface kelola penduduk dapat melakukan beberapa fungsi pengelolaan seperti menampilkan daftar data tersimpan, menambahkan data baru, melihat detail, mengubah data dan menghapus data, serta dapat melakukan pencarian data pada daftar data tersimpan. Dan dapat dilakukan pengunduhan data dalam format excel. 


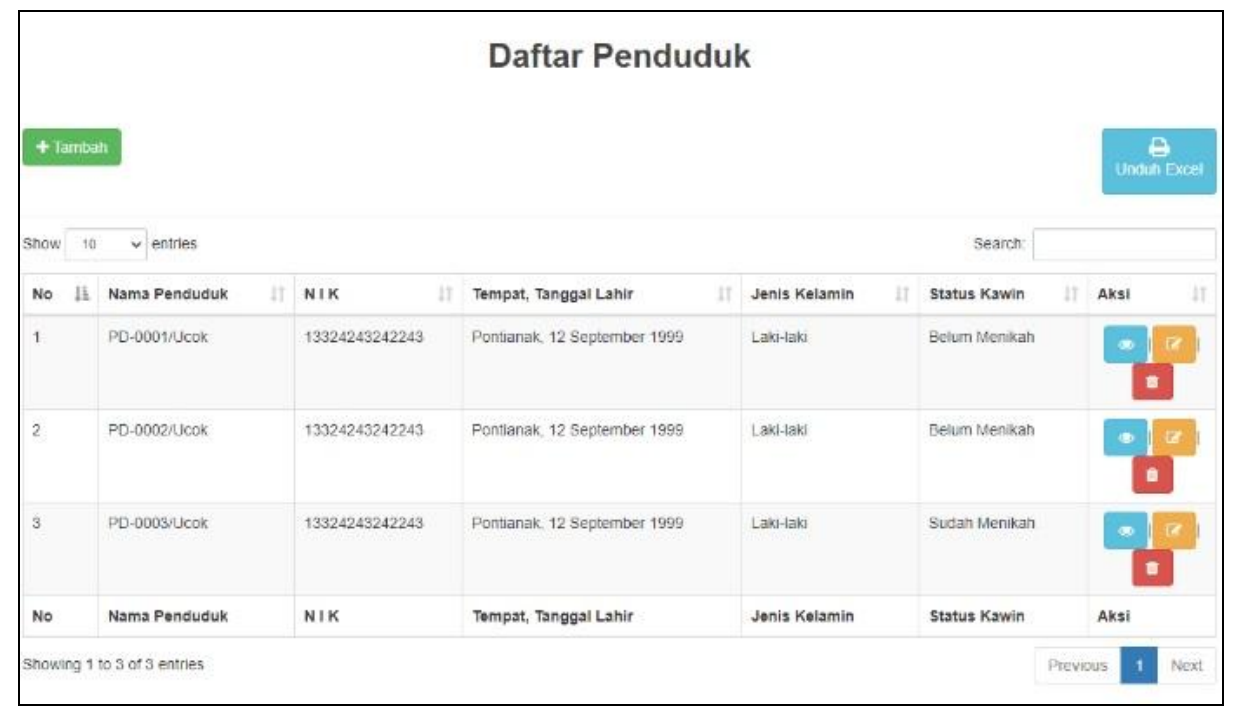

Gambar 5. Interface Daftar Kelola Data Penduduk

\section{Kesimpulan}

Berdasarkan hasil penelitian dan pembahasan dapat ditarik kesimpulan bahwa, dengan menggunakan pemodelan UML dapat memberikan gambaran mengenai proses rancangan, baik dari awal analisa dan desain, sehingga dari analisa yang dilakukan didapatkan penjabaran secara rinci terkait apa yang dibutuhkan oleh sistem. Setelah pemodelan dalam perancangan sistem ini selesai, maka akan lebih terarah dalam membuat sistem tersebut dalam pendataan pengelolaan administrasi kependudukan khusunya di Kantor Desa dan dari situ pula pengujian dengan mudah dilakukan untuk menganalisasi kekurangan sistem kedepannya.

\section{Daftar Pustaka}

[1] E. B. Pratama and Kadarusman, "Pemodelan Sistem Informasi Penilaian Prestasi Kerja Pegawai Kantor Dinas Komunikasi dan Informatika (Diskominfo) Kota Pontianak," J. Tek. Inform. Kaputama, vol. 4, no. 1, pp. 55-63, 2020.

[2] A. Rozaq, K. F. Lestari, and S. Handayani, "Sistem informasi produk dan data calon jamaah haji dan umroh pada Pt. Travellindo Lusiyana Banjarmasin berbasis web," J. POSITIF, vol. 1, no. 1, pp. 1-13, 2015.

[3] M. Sudin, "Aplikasi Administrasi Pendidikan Sebuah Tinjauan Filosofis Dalam Terminologi Kontemporer," J. Tarb., vol. 11, pp. 163-177, 2014.

[4] E. Amalia and Y. Supriatna, "Perancangan sistem informasi administrasi kependudukan sebagai pengembangan egovernment," in Prosiding Seminar Ilmu Komputer dan Teknologi Informasi, 2017, vol. 2, no. 1, pp. 81-85.

[5] Q. Siddique, M. Iaeng, and A. Main, "Unified Modeling Language to Object Oriented Software Development," Int. J. Innov. Manag. Technol., vol. 1, no. 3, pp. 264-268, 2010.

[6] E. B. Pratama and A. Hendini, "Pemodelan Sistem Informasi Layanan Masyarakat (Silam) Pada Kantor Desa Untuk Meningkatkan Pelayanan,” Klik - Kumpul. J. Ilmu Komput., vol. 6, no. 1, p. 49, 2019.

[7] R. M. Salah, G. R. Alves, P. Guerreiro, and I. Gustavsson, "Using UML models to describe the VISIR system," Int. J. Online Eng., vol. 12, no. 6, pp. 34-42, 2016.

[8] T. A. Kurniawan, "Pemodelan Use Case (UML): Evaluasi Terhadap beberapa Kesalahan dalam Praktik," J. Teknol. Inf. dan Ilmu Komput., vol. 5, no. 1, p. 77, 2018.

[9] T. B. Kurniawan, "Perancangan Sistem Aplikasi Pemesanan Makanan Dan Minuman Pada Cafetaria No Caffe Di Tanjung Balai Karimun Menggunakan Bahasa Pemograman,” J. TIKAR, vol. 1, no. 2, pp. 192-206, 2020.

[10] Zulkifli, "Rancang Bangun Website E-Learning Dengan Pemodelan Uml (Studi Kasus Di STKIP Muhammadiyah Muara Bungo),” J. Inf. Technol. Comput. Sci., vol. 1, no. 2, pp. 159-167, 2018.

[11] I. G. Tofik Isa and G. P. Hartawan, "Perancangan Aplikasi Koperasi Simpan Pinjam Berbasis 
Web," Ilm. Ekon. Vol. 5 Ed. 10, vol. 5, no. 10, pp. 139-151, 2017.

[12] Suendri, "Implementasi Diagram UML (Unified Modelling Language) Pada Perancangan Sistem (Studi Kasus : UIN Sumatera Utara Medan),” J. Ilmu Komput. dan Inform., vol. 3, no. 1, pp. 1-9, 2018. 